\title{
Maternal and Fetal Leptin Level Correlation with Fetal
}

\section{Macrosomia}

Manal S. Swelem, ${ }^{*}$ Yasser S. Elkassar, ${ }^{\star}$ Abd El-moneim A. Fawzy, ${ }^{\star}$ Akram A Deghady, ${ }^{\star *}$ Ahmed

S. Abd El-atty. *

\begin{abstract}
:
Background:Leptin seems to be a critical factor for overall fetal development. Macrosomia may place the mother and fetus or neonate at risk for adverse outcomes. Aim: to test if leptin level is implicated in macrosomia. Method: The sample comprised25 cases delivered full term normal weight infants, and 25 cases delivered full term macrosomicinfants. Maternal serum samples and fetal cord samples were withdrawn immediately after birth of the full term infants. Results: Fetal leptin level was higher in macrosomic infants than normal weight infants. No difference in maternal leptin level between both groups was observed. Conclusion: Leptin levels related directly to quantity of body fat tissue in fetal macrosomia as there is leptinresistence causing elevated leptin levels.
\end{abstract}

\section{INTRODUCTION}

Leptin is a $16-\mathrm{kD}$ protein produced predominantly in white adipose tissue and, to a lesser extent, in the placenta, skeletal muscle, and stomach fundus in rats. Leptin has a myriad of functions in carbohydrate, bone, and reproductive metabolism that are still being unraveled, but its role in body weight regulation is the main reason it came to prominence. ${ }^{(1-3)}$

The major role of leptin in body-weight regulation is to signal satiety to the hypothalamus and, thus, reduce dietary intake and fat storage while modulating energy expenditure and carbohydrate metabolism to prevent further weight gain. ${ }^{(4-6)}$ Unlike the $\mathrm{Ob} / \mathrm{Ob}$ mouse model in which this peptide was first characterized, most humans who are obese are not leptin deficient but rather leptin resistant. Therefore, they have elevated circulating

\footnotetext{
* Department of Obstetrics \&Gynecology, El-Shatby hosp, Alexandria, Egypt

${ }^{* *}$ Department of clinical and chemical pathology Alex. University, Egypt
} 
levels of leptin. Elevated circulating leptin in obesity reflects leptin receptor resistance. Leptin receptors, members of the gp130 family of cytokine receptors, are expressed in the hypothalamus. ${ }^{(7-8)}$

Leptin, the ob gene product, plays an important role in the regulation of body fat mass and weight. In previous studies, it was demonstrated that leptin is detectable in human fetal cord blood as early as at 18 weeks of gestation. ${ }^{(9-11)}$

Leptin seems to be a critical factor for overall fetal development, as well as the evolution and maintenance of the pregnancy, while the regulation and the dynamics of the secretion of the hormone during pregnancy are extremely complex processes. The hormone is produced in both maternal and fetal adipose tissues and in the placenta, while its receptors are expressed in the uterine endometrium,trophoblast and the fetus. ${ }^{(12)}$

Fetal macrosomia has been defined in several ways. The definitions include birth weight greater than $4000 \mathrm{~g}$ or greater than $90^{\text {th }}$ percentile for the newborn adjusted for race, sex, and gestational age. ${ }^{(13,14)}$

Based on these definitions, macrosomia occurs in $1-10 \%$ of all deliveries. Macrosomia may place the mother and fetus or neonate at risk for adverse outcomes asmaternal risks include risks associated with the passage of a large fetus through the birth canal. Macrosomic fetuses place the mother at increased risk of birth canal (e.g.perineal, vaginal, cervical) lacerations, Fetal risks associated with macrosomia include birth trauma (3-7\%), including shoulder dystocia (9.2-24\%); brachial plexus injuries (1-4\%); and death $(0.4 \%) .{ }^{(157)}$,Neonatal risks associated with macrosomia include hypoglycemia (50\%), hematological disturbances (i.e. polycythemia), and electrolyte disturbances (up to $50 \%$ ).

Childhood and adolescence risks include developing diabetes and obesity later in life and deserves careful long-term follow- 
up care. Antenatal risk factors reportedly may predict macrosomia at birth. Identification of those at-risk pregnancies may allow intervention to reduce the risk, to provide appropriate counseling, and to implement appropriate plans for monitoring and follow-up care during pregnancy and after delivery. ${ }^{(13,14)}$

\section{Aim of the study:}

The aim of this studywas toinvestigate thecorrelation between the circulating levels of leptin hormone in the maternal and cord serum and macrosomia of the full term newborns, in medically free mothers.with the ultimate goal to know if leptin level is implicated in macrosomia.

\section{MATERIALS AND METHODS}

This study which is a case control studywas conducted on a group of 50 medically free pregnant women having antenatal care in the obstetrics unit of the hospital El shatby University of Alexandria and had delivery at the hospital. Allparticipants werefully counseledabout thestudy and an informed consent wasobtainedprior to participation in the study.

\section{INCLUSION CRITERIA:}

- Medically free mothers having full term macrosomic infants.

- Medically free mothers having full term normal weight infants.

- Any type of delivery whether cesarean or normal vaginal delivery.

- Any type of anesthesia during delivery.

\section{EXCLUSION CRITERIA:}

- Other medical causes of macrosomia of the infants, e.g. (DM).

- Preterm and postdate infants.

- Obese patients $(\mathrm{BMI}>30)$.

- $\mathrm{RH}$ incompatibility.

- Preeclampsia

The selected patients were subdivided in two groups:

Group A (control group):25 cases delivered fullterm normal weight infants.

Group B (study group):25 cases delivered fullterm macrosomic infants.

Maternal serum samples and fetal cord 
samples were withdrawn immediately afterbirth of the full term infants

All patients who participated in this study received the standard ante partum care in the form of complete history taking including obstetric history of previous deliveries (number, type, complications, history of abortion), general examination (blood pressure, pulse, weight, height), laboratory investigations (complete blood picture, blood group, $\mathrm{RH}$, urine analysis, screening for diabetes), ultrasound examination to determine (gestational age, viability, fetal anomalies, liquor amount, placental position, fetal lie, presentation).

Screening for gestational diabetes was done at 24-28 weeks which is the optimal time for screening for gestational diabetes using one hour $50 \mathrm{~g}$ oral glucose tolerance test(O'sullivan test) followed by $100 \mathrm{~g} 3$ hour oral glucose tolerance if the result was abnormal to diagnose diabetes, ${ }^{(15)}$ values for screening and diagnosing diabetic patients were as follow:
For one hour $50 \mathrm{~g}$ oral glucose tolerance test as a screening test:

1 hour: less than $140 \mathrm{mg} / \mathrm{dL}$

For $100 \mathrm{~g} 3$ hour oral glucose tolerance

test:

Fasting 95 mg/dl

1 hour $180 \mathrm{mg} / \mathrm{dl}$

2 hours $155 \mathrm{mg} / \mathrm{dl}$

3 hours $140 \mathrm{mg} / \mathrm{dl}$

Immediately after delivery patients of group A and group B included in our study had:

1. Umbilical cord samples of the fetus were withdrawn immediately after birth.

2. Maternal serum samples were withdrawn immediately after birth.

3. Samples were stored at -20 celesius in the laboratory till analysis.

4. Samples were analyzed by a solid phase ELISA designed to measure human leptin in serum and plasma.it employs the quantitative sandwich enzyme immunoassay principle.

Quantitative data were describedusing 
mean and standard deviation.

Qualitative data were described using number and percent. Comparison between different groups regarding categorical variables was tested using Chi-square test.

\section{RESULTS}

Table 1: Comparison between the two studied groups according to some selected variables.

\begin{tabular}{|c|c|c|c|c|c|}
\hline & \multicolumn{2}{|c|}{ Normal } & \multicolumn{2}{|c|}{ Macrocosmic } & $\mathbf{P}$ \\
\hline \multicolumn{6}{|l|}{ Fetal Leptin } \\
\hline Min - Max & \multicolumn{2}{|c|}{$0.50-26.50$} & \multicolumn{2}{|c|}{$5.50-100.0$} & \multirow{3}{*}{$<0.001^{*}$} \\
\hline Mean \pm SD & \multicolumn{2}{|c|}{$7.82 \pm 7.36$} & \multicolumn{2}{|c|}{$37.74 \pm 32.44$} & \\
\hline Median & \multicolumn{2}{|c|}{6.0} & \multicolumn{2}{|c|}{26.0} & \\
\hline \multicolumn{5}{|c|}{ Maternal Leptin } & \multirow{4}{*}{0.107} \\
\hline Min - Max & \multirow{2}{*}{\multicolumn{2}{|c|}{$\begin{array}{c}5.0-67.0 \\
19.75 \pm 15.36\end{array}$}} & \multicolumn{2}{|c|}{$8.25-70.0$} & \\
\hline Mean \pm SD & & & 23.5 & 13.48 & \\
\hline Median & \multicolumn{2}{|c|}{18.0} & \multicolumn{2}{|c|}{22.25} & \\
\hline \multicolumn{6}{|l|}{ Age (years) } \\
\hline$<25$ & 10 & 40.0 & 0 & 0.0 & \\
\hline $25-30$ & 15 & 60.0 & 17 & 68.0 & $p<0.001$ \\
\hline$\geq 30$ & 0 & 0.0 & 8 & 32.0 & \\
\hline $\operatorname{Min}-\operatorname{Max}$ & \multicolumn{2}{|c|}{$21.0-30.0$} & \multicolumn{2}{|c|}{$26.0-36.0$} & \\
\hline Mean \pm SD & \multicolumn{2}{|c|}{$25.76 \pm 2.74$} & \multicolumn{2}{|c|}{$29.68 \pm 3.22$} & $p<0.001$ \\
\hline Median & \multicolumn{2}{|c|}{26.0} & \multicolumn{2}{|c|}{28.0} & \\
\hline \multicolumn{6}{|l|}{ Gravidity } \\
\hline$<3$ & 17 & 68.0 & 9 & 36.0 & \\
\hline$\geq 3$ & 8 & 32.0 & 16 & 64.0 & \\
\hline Min - Max & \multicolumn{2}{|c|}{$1.0-3.0$} & \multicolumn{2}{|c|}{$1.0-5.0$} & \\
\hline Mean \pm SD & \multicolumn{2}{|c|}{$2.08 \pm 0.76$} & \multicolumn{2}{|c|}{$2.72 \pm 0.98$} & $p=0.016$ \\
\hline Median & \multirow{2}{*}{\multicolumn{2}{|c|}{2.0}} & \multicolumn{2}{|c|}{3.0} & \\
\hline \multicolumn{5}{|l|}{ Parity } & \\
\hline$<2$ & 18 & 72.0 & 9 & 36.0 & \\
\hline$\geq 2$ & 7 & 28.0 & 16 & 64.0 & \\
\hline $\operatorname{Min}-\operatorname{Max}$ & & & & & \\
\hline Mean \pm SD & & .73 & & 0.98 & ${ }^{N W W} p=0.009$ \\
\hline Median & & & & & \\
\hline Mode of de & & & & & \\
\hline NVD & 21 & 84.0 & 4 & 16.0 & \\
\hline CS & 4 & 16.0 & 21 & 84.0 & $p<0.001^{*}$ \\
\hline
\end{tabular}

$p: p$ value for Mann Whitney test for comparing between the two studied groups

*: Statistically significant at $p \leq 0.05$ 


\section{DISCUSSION}

The mechanism of fetal growth and the factors regulating fetal growth are not certain yet. There are several factors that have been investigated repeatedly with controversial outcomes; leptin is among these factors.

We found a statistically significant correlation between fetal plasma leptin levels and neonatal birth weight, which suggests that leptin levels related directly to quantity of body fat tissue in fetal macrosomia.

A strong positive correlation between umbilical cord leptin levels and birth weight suggests that leptin is synthesized by fetal tissue; however, studies recently found expression of leptin messenger and leptinimmunoreactive proteins in placental tissue. $^{(16)}$

Our results was consistent with what was proved by Weyermann, et al (2006). ${ }^{(17)}$

We didn't find a statistically significant difference between the two groups of mothers, so maternal leptin level is not related to fetal birth weight, this is consistent with what was proved in previous studies. ${ }^{(18)}$

A significant correlation was found between high gravidity and high parity and fetal macrosomia, that means that high gravidity and high parity is a risk factor for macrosomia as proved in previous studies. ${ }^{(18,19)}$

A significant correlation was found between macrosomia and cesarean type of delivery as $84 \%$ of macrosomic babies had cesarean delivery this is consistent with what was proved byCombs (1993). ${ }^{(20)}$

A significant correlation was found between maternal age and fetal macrosomia as older mothers had macrosomic babies this proves that high maternal age is a risk factor for macrosomia as proved in previous study. ${ }^{(21)}$

\section{CONCLUSION}

From this study we concluded that:

1- A significant correlation was found between fetal cord leptin level and fetal macrosomia. 
2- No significant correlation was found between maternal serum leptin level and fetal weight.

3- No correlation was found between maternal and fetal leptin level that is consistent with non-communicatory two compartment feto-placental circulation.

\section{RECOMMENDATIONS}

- Fetal leptin level is related to fetal weight and can be depended upon for diagnosing fetal macrosomia.

- Maternal weight before pregnancy is related to fetal weight so maternal weight control is beneficial for fetal weight control.

\section{REFERENCES}

1. Clapp JF, Kiess W. Cord blood leptin reflects fetal fat mass. J SocGynecol Invest. 1998;5:300-3.

2. Harris RB. Leptin, much more than a satiety signal. Annu Rev Nutr. 2000; 20:45-75.

3. Farooqi IS, O'Rahilly S. Leptin: a pivotal regulator of human energy homeostasis. Am J ClinNutr. 2009;89:980-4.

4. Friedman JM, Halaas JL. Leptin and the regulation of body weight in mammals. Nature 1998;95:763-70.

5. Schwartz MW, Woods SC, Porte D. Central nervous system control of food intake. Nature. 2000;404:661-71.
6. Myers MG. Leptin receptor signaling and the regulation of mammalian physiology. Recent ProgHorm Res. 2004;59:287304.

7. Münzberg $H$, Myers MG. Molecular and anatomical determinants of central leptin resistance. Nat Neurosci. 2005;8:566-70.

8. Morris DL, Rui L. Recent advances in understanding leptin signaling and leptin resistance. Am J PhysiolEndocrinol. Metab. 2009;297:1247-59.

9. Rui Z, Hong-gang M.Preliminary study of the relationship between cord blood leptin, IGF- I and fetal growth and development. Journal of Clinical Pediatrics. 2009;6:17.

10. Mantzoros CS, Rifas-Shiman SL, Williams CJ. Cord blood leptin and adiponectin as predictors of adiposity in children at 3 years of age: a prospective cohort study. Pediatrics.2009;123:682-9.

11. Yinghua, DM, Chengyun F.Determination of umbilical serum leptin level and the relationship between leptin and $\mathrm{T}_{3}, \mathrm{~T} 4$, TSH level in term newborns. Jiangxi Medical Journal 2009; 05:422-4.

12. Henson MC, Castracane VD. Leptin in pregnancy: an update. BiolReprod 2006; 74:218-29.

13. Heiskanen N, Raatikainen K, Heinonen $\mathrm{S}$ : Fetal macrosomia--a continuing obstetric challenge. Biol Neonate 2006; 90:98-103.

14. Zhang X, Decker A, Platt RW, et al. How big is too big? The perinatal consequences of fetal macrosomia. Am J ObstetGynecol. 2008;198:517-6.

15. Screening for gestational diabetes mellitus: U.S. Preventive Services Task Force recommendation statement. Ann Intern Med. 2008;148:759-65.

16. HensonMC,SwanKF,O'NeilJS.Expressio $\mathrm{n}$ of placental leptin and leptin receptor transcripts in early pregnancy and at term. ObstetGynecol. 1998;92:1020-8.

17. Weyermann MC, Brenner BH. 
Adiponectin and leptin in maternal serum, cord blood,and breast milk.Clin Chem,2006;52:2059-102.

18. Yoshimitsu N, Douchi T, Kamio M, et al. Differences in umbilical venous and arterial leptin levels by mode of delivery. ObstetGynecol. 2000; 96:342-5.

19. Thomson AM, Billewicz WZ, Hytten FE. The assessment of fetal growth. J
Bstet Gynaecol Br Commonw. 1968; 75(9):903-16 .

20. Di Renzo GC, Rosati A, Sarti RD, et al. Does fetal sex affect pregnancy outcome? Gend Med. 2007;4(1):19-30.

21. Institute of Medicine. Nutritional status and weight gain. In: Nutrition During Pregnancy. National Academies. Press; 2012; 27-233. 